\title{
12. THE PURPOSE OF EMPATHY FORMATION AND ITS ROLE IN THE DEVELOPMENT OF MODERN TEACHERS FROM PRIMARY CLASSES
}

\author{
Iulia Postolache ${ }^{275}$
}

\begin{abstract}
The development of empathy is directly depended on the possibility of knowing the roles, establishing relationships, feeling emotions in different social situations. The functions of empathy allow an effective communication between teachers and students, strengthening mutual trust by analyzing their actions in the process of discussion. However, all these noted, can be achieved in the process of communication between the speaker and the listener, the teacher and the student. Empathy is characteristic to teachers who are able to think about their friend, not to be selfish. Empathetic teachers can feel what others feel, identify their emotions, help others to solve problems and imagine themselves in someone's situation. Empathetic teachers try to be in somebody's coat and realize what students would feel in certain situations. Empathy can be felt all the time and it's necessary to modern people, because everybody needs to accept himself and to respect others.
\end{abstract}

Key words: empathy, teachers, relationships, communication, primary classes

\section{Introduction}

The contemporary society, in which man is the main driving force of technology, predisposes to outline of beings who are on the verge of feeling and inner life.This risk can also be spread in other spheres, where the function of the job requires more than the simple fulfillment of the duties.In this order of ideas, the modern educational institution aims to support teachers for a spiritual, valuable opening to students and parents.Or, the child, the little schoolboy develops his personality by having his own teacher as a model, which gives him is the warmth of his heart, illuminating his path of knowledge and discovery in life. Contextually, empathy the possibility of being able to share another's joy and sadness through personal experience.From here comes the necessity for training and development of this quality in the teachers of primary classes.That's why, being empathetic with your own pupils is an aspiration of teachers, despite modern times, and a desire of parents, who expect the teacher to be a parent for his child at school.As a result, empathy can generate compassion for our neighbor.

\section{Discussions}

Modern teachers of primary classes need empathy in their professional activity, but they are also required to form and develop empathy for their disciples. A pupil without desire to help his or her colleague in certain situations becomes selfish, and a class of selfish pupils, spiritually isolated pupils risks evolving into

\footnotetext{
275 Candidate Doctoral, "Ion Creangă" State Pedagogical University from Chişinău, Republic of Moldavia, Assistante, Alecu Russo" State University from Bălţi, Republic of Moldavia, email: iulia.postolachi@mail.ru
} 
a dismembered and unenforceable generation, because progress is made through collaboration and unity.It is obvious that lately, more and more students prefer to work individually, not in a group or in a team, which distances them from their interests, the horizon of knowledge, the feelings of other colleagues.

Once empathy comes to the understanding of establishing emotions of other people,the way in which it is characterized derives from the way in which the emotions themselves are repressed. Thus, the ability to imagine yourself as another person is a complicated imaginative process. However, the possibility of recognizing emotions is probably innate and can be obtained unconsciously. So, empathy is different from sympathy, pity and emotional contagion, because it reflects the feeling of compassion for other people, namely the desire to see them happier. Researcher M. Robu [7] presents empathy in four ways:

1. general or aperceptive empathy;

2. natural or empirical empathy, through which they are assigned to the objects force and movement, that is, their own attitude, of a human type;

3. empathy of disposition, which consists of sensory reactions such as the definition of colors as hot or cold, cheerful or sad;

4. transposing empathy, defined as a multiplication of the self, a transposition in the probable state of other.

Empathy is an ability to predict other people's behavior based on knowledge of psychological dispositions (perceptions, thoughts, feelings, attitudes), the ability of people to understand the feelings of others and the ability to anticipate the behavior of others in given situations $[7,8]$. The concept of empathy has also been studied by art specialists, who outline the idea of reflecting life in the creation of authors, in order to awaken the recipient's empathy, that is, re-living by transposing into the psychology of the other their own explanation.

Therefore, empathy is undoubtedly an important ability that allows us to translate into the psychology of others to understand what they think, feel and act. It allows us to understand social relationships, specify the behavior of peers and express appropriate emotions in response to their emotions [3, 4]. Taking into account the conceptual aspects noted above, we reiterate the role of empathy development of primary school teachers, who have a duty to educate the next generation.So, by being aware of the behavior of their pupils, the teachers can guide the disciples through tips, games, parables, role-playing games, the moral of literary works, towards understanding, love and the desire to help their neighbor, because, in turn, to be helped too.Thus, the teachers know their group of pupils, but, the more they know themselves.Empathy develops in the teachers with the didactic experience, with the active involvement in the school life, even with the reading of the studies in the psycho-pedagogical field.Being empathetic with pupils in educational institutions increases not only success, but also esteem, respect and school results. Empathy should not be confused with tolerance, for empathy generates wisdom and love, reason and balance, joy and tranquility.

So, modern teachers of primary education need to support their 
relationships with pupils and even their parents by manifesting empathic behavior. However, empathy must become a virtue of teachers, not just a professional tool. Sincerity, patience, love and wisdom develop empathetic spirit, qualifying it to a level of hard value. Along with the empathic nature, modern teachers also train, form and develop communication skills. The correct expression in the discussions supports the motor, intellectual and affective development, because the communication includes the two primary aspects, to give and receive, to express and to receive, to say and to understand, that is to say, to relate to the lived experience. Certainly, teachers communicate daily with their pupils, not only within the classroom, but also outside, so the message of speaking will necessarily externalize the inner feelings as a result of empathy. The empathy-communication relationship is a consequence of human living, reinforcing the explanations offered by the specialized dictionaries by which empathy is defined as an implicit way of communication, without replacing the explicit one, completing and enhancing it [9].

\section{Results}

The pedagogical mastery combines effective communication in the lesson with the empathetic attitude of the teacher, by which he selects the working methods, the teaching strategies and even the involvement of the students in the lesson. Through the discussion with the pupils, the teacher sets his scenario according to the mentioned empathic functions.Hence the argument that empathy is the ability to understand the feeling of another person in implicit way.

In the situation when the pupils have the uncertainty that they are understood, when they cannot participate directly in the lessons or extracurricular activities due to the communication blockages, the problems of expression, of clear speech, the empathy of the teacher becomes a support for the school, a real chance to solve the problem of the disciple by means of explanatory speeches, by his hypostasis in the role of the pupil, by offering the examples in life, when people developed as personality by accepting his self[ 9].

Presenting path of the mechanism of empathy, necessary to be known by modern teachers, we observe that, empathy has a certain way of unfolding, which is based on a certain cognitive-informational content, with a certain functionality. As a result, the cognitive-informational content is given by the relationship between the model that will be empathized and the subjective relive of this model. The mechanism of the empathic process involves the following aspects: cognitive, anticipatory, communication, affective contagion or related to the need for performance, this again emphasizing the complexity of the phenomenon of empathy. As a result, the psychic product, the effect reached is the self that relives the emotions, thoughts and actions of the partner, a product that can materialize also in the actions of the individual who empathized.

In the instructive-educational process, empathy involves a convergence of emotions and thoughts in the direction of the model with which the teacher 
empathizes, a mechanism that, in the computerized age of the contemporary world, is increasingly difficult to achieve due to social and virtual distances. In general, it was found that the genesis of empathic competence is favored by three categories of conditions:

a) external, relative to the model of empathizing;

b) internal, the psychological premises of the one who empathizes;

c) circumstantial, related to the belief in the convention.

So, analyzed separately, these categories of conditions are presented as follows:

a) The contact with the model of empathy can be achieved through the direct, implicit perception of the partner, obvious perceptions in the doctor-patient relationship, teacher-student; by representing the model that is evoked, being the case of the actor who plays a role; by means of imagination such as the case of drawing a literary character by the writer. However, for the informational value of the model to be empathized, it is necessary that the object of empathy be placed on a relatively known terrain, and at a medium distance, neither too large nor too small.

b) The internal condition or the conditions regarding the individual's predispositions refer to: high sensitivity for emotional experiences, emotional experience, evocative and imaginative possibilities, desire and need to establish emotional contact and to communicate, the possibility of self-knowledge [10].

Arguing those noted above, we support the conclusions of researcher Roșca A. [6] who states that there are currently many scientific concerns that have led to the elaboration of programs of directed training of this capacity, programs that target the doctors, the teachers, psychologists, parents who want to limit some disagreements in understanding their own children, etc. Being successfully applied in various countries, these programs bring excellent results. And the intention of perfecting such programs is a major concern, in the desire to meet a natural, specifically human need - the need for empathy.

Therefore, empathy facilitates the expression of emotions, beliefs, values and improves communication between parents and children. An indicator of empathy is the pupil's feeling that is understood and accepted. The empathetic, open and warm attitude leads to the formation of positive relationships with others. We must not forget that empathy is essential in educating students for optimal adaptation to the social environment, in maintaining mental and emotional health, in developing and maintaining well-being [11].

Mureşan A. [2], also states that the desire to be empathetic is a prerequisite for optimizing teachers' relationships with pupils and a condition of effective communication. The empathy of the teachers is a spontaneous and rapid way of entering the pupil's state of mind. Thus, there is the possibility of a relatively correct anticipation of the partner's behavior by understanding the intentions, feelings and thinking of others, an extremely important fact in establishing desirable interpersonal relationships and, consequently, establishing a proper 
behavioral strategy towards the students.It is surprising that teachers can evaluate relatively correctly what the pupil feels, lives, thinks, can be transposed into his situation and, through effective communication, create appropriate conditions of influence. For teachers, it is necessary to know exactly how the pupil is, but also how the pupil thinks he is, because only understanding him can influence him. Like any capacity, empathic capacity has an inherent psychophysiological potential, but it is realized and developed in the process of interpersonal knowledge and, if the subject intends, through self-directed alternation. Between empathic capacity and empathic behavior there may be concordance or discrepancy, congruence or incongruity. Approaching each pupil allows the individual to know and treat the pupil, allowing to maintain a normal relationship with the class and strengthening the interpersonal relationships in the class.

But any exaggeration in this regard inevitably leads to pedagogical failure. The lack of empathic capacity determines a subjective interpretation of the individual and grouped reality and leads to accidental educational measures. The empathic competence of the teachers is required at all times of the lesson and in all the communication directions: from teacher to pupils and from pupils to teacher. Thus, in teaching, the teacher selects and measures the information he provides to the pupils to be assimilated based on the assimilation possibilities of the pupils, possibilities unevenly distributed; it cannot teach neither for those with high skills, nor for those who must be brought to a minimum level of training. Thus, the climate created by the behavior of the teachers by smile, approving movements of the head, the warmth of the voice, the visual contact with the students, increase the concentration effort to cope with the task of producing joy. The steps taken by the teaching staff take into account the possible pace of work of the pupils, and the tasks are a difficulty that can be overcome with a moderate effort [2].

In this regard, Cristea V. [1], Pănişoara I. [5, p. 195] argue that empathy is among special abilities, which are not accessible to anyone, being received through considerable efforts. Certainly, empathy is much closer to us than we think, it is even our preverbal and nonverbal language, that is, we have relied heavily on it before learning to speak, being vital to our survival and development. Without her help, we would not have reached where we are now, we would not have been able to grow, relate, communicate. It seems to us that it is reserved exclusively for certain people only because now, at maturity, I forgot about it, using it unconsciously, automatically, and sometimes in distorted ways.

Empathy is a wonderful gift, a way of communication so fine and profound that, if we allowed it to manifest itself consciously, it would lead us through a free, cursive life, would help us to know ourselves at some unexpected levels and it would open our gates to an understanding and feeling of others that breaks down the barriers and boundaries between us, established through comparisons and competition. Summarizing the above, we argue that empathy is a difficult term to explain, because it encompasses many facets, from being sensitive to the other's 
deep feelings and understanding them, to feeling strongly and disturbingly the visible emotions of those in around. Therefore, empathy may seem like a magical ability to receive information about others, because the education we receive lacks the conception of self-orientation, the place where all our abilities and talents are nourished.

\section{Conclusions}

Finally, we conclude that empathy is a continuous celebration of our open, spiritual nature. Empathy allows us to enjoy life, to live fully, to vibrate with sensitivity to listening to music, watching the beauty of the surroundings, watching a movie or reading a book. It urges us to immerse ourselves in the other's gaze and to feel his infinity. It allows us to get excited in front of a work of art. It gives us the privilege of discovering what lies within the soul of the one next to us. Thus we can look at the world with more understanding and compassion, we can feel satisfied with what we have, contributing to the spiritual growth of humanity. So, to become aware of its role and to enjoy the gift of feeling, loving, living in freedom, peace and quiet.

\section{References}

1. Cristea V., ( 2012 ),Empathyhttp://analizapsy.blogspot.com/2012/03/empatia. html, accesat 19.07.2019

2. Mureșan A., (2014), https://concursurilecomper.ro/rip/2014/februarie2014/21Muresan Adela Gabriela-Empatia.pdf, accesat 19.07.2019

3. Mândâcanu V., (2009), Master Teacher,Editura Pontos, Chișinău

4. Mitrofan N. , ( 1998),Pedagogical aptitude,Editura Academiei, București

5. Pânișoară I., ( 2017), The teacher's guide,EdituraPolirom, Iași, ISBN 978-97346-6698-0, pag.191, 195

6. Roșca A., (2012), Empathy,http://www.infopsihologia.ro/2012/11/empatia/, accesat01.07.2019

7. Robu M., (2008), Empathy in education, modern pedagogical needs, Editura: Didactica Publishing House, 103 p., ISBN 978-973-88899-7-2

8. https://ro.wikipedia.org/wiki/Empatie, accesat 19.07.2019

9. http://www.creeaza.com/referate/psihologie-psihiatrie/Empatia-definitii-sidelimitar516.php, accesat 19.07.2019

10.https://biblioteca.regielive.ro/referate/comunicare/empatia-si-rolul-sau-indezvoltarea-inteligentei-emotionale-a-liderului-307356.html, accesat 19.07.2019 11. https://performante.ro/cum-dezvoltam-empatia-la-copil, accesat01.07.2019 